\title{
Hierarchical creep cavity formation in an ultramylonite and implications for phase mixing
}

\author{
James Gilgannon $^{1,2}$, Florian Fusseis ${ }^{2}$, Luca Menegon ${ }^{3}$, Klaus Regenauer-Lieb ${ }^{4}$, and Jim Buckman ${ }^{5}$ \\ ${ }^{1}$ Institute of Geological Sciences, University of Bern, Baltzerstrasse 1+3, 3012 Bern, Switzerland \\ ${ }^{2}$ School of Geosciences, The University of Edinburgh, Grant Institute, Edinburgh EH9 3JW, UK \\ ${ }^{3}$ School of Geography, Earth and Environmental Sciences, Plymouth University, Plymouth PL4 8AA, UK \\ ${ }^{4}$ School of Petroleum Engineering, The University of New South Wales, Kensington NSW 2033, Australia \\ ${ }^{5}$ Institute of Petroleum Engineering, Heriot-Watt University, Edinburgh EH14 4AS, UK
}

Correspondence: James Gilgannon (james.gilgannon@geo.unibe.ch)

Received: 22 August 2017 - Discussion started: 28 August 2017

Revised: 30 October 2017 - Accepted: 14 November 2017 - Published: 19 December 2017

\begin{abstract}
Establishing models for the formation of wellmixed polyphase domains in ultramylonites is difficult because the effects of large strains and thermo-hydro-chemomechanical feedbacks can obscure the transient phenomena that may be responsible for domain production. We use scanning electron microscopy and nanotomography to offer critical insights into how the microstructure of a highly deformed quartzo-feldspathic ultramylonite evolved. The dispersal of monomineralic quartz domains in the ultramylonite is interpreted to be the result of the emergence of synkinematic pores, called creep cavities. The cavities can be considered the product of two distinct mechanisms that formed hierarchically: Zener-Stroh cracking and viscous grain-boundary sliding. In initially thick and coherent quartz ribbons deforming by grain-size-insensitive creep, cavities were generated by the Zener-Stroh mechanism on grain boundaries aligned with the $Y Z$ plane of finite strain. The opening of creep cavities promoted the ingress of fluids to sites of low stress. The local addition of a fluid lowered the adhesion and cohesion of grain boundaries and promoted viscous grain-boundary sliding. With the increased contribution of viscous grainboundary sliding, a second population of cavities formed to accommodate strain incompatibilities. Ultimately, the emergence of creep cavities is interpreted to be responsible for the transition of quartz domains from a grain-size-insensitive to a grain-size-sensitive rheology.
\end{abstract}

\section{Introduction}

Microstructural observations of shear zones in nature and experimental investigations of monomineralic systems in the laboratory have demonstrated that the evolution of a ductile fault rock through the mylonite series can entail a switch from a dislocation creep-controlled (grain-size-insensitive, GSI) to a diffusion creep-controlled (grain-size-sensitive, GSS) bulk rheology (e.g. Etheridge and Wilkie, 1979; Poirier, 1980; Kilian et al., 2011). In quartzo-feldspathic rocks at mid-crustal conditions, this progressive evolution often leads to the development of distinct microstructural elements in close spatiotemporal proximity: feldspathic porphyroclasts, monomineralic quartz bands and well-mixed, fine-grained polyphase domains (Fig. 1). Each of these elements have been shown to accommodate deformation differently, e.g. feldspars fracture and react, quartz experiences GSI creep and the polyphase domains deform by GSS processes (Mitra, 1978; Kerrich et al., 1980; Behrmann and Mainprice, 1987; Fliervoet et al., 1997; Stipp et al., 2002; Tullis, 2002). Generally speaking, with ongoing deformation the proportion of fine-grained material deforming by GSS creep increases synkinematically so that the polyphase domains form an interconnected weak layering. It is the establishment of these well-mixed, anti-clustered polyphase domains that is recognised to ultimately promote a switch in the bulk rheology of the rock (Handy, 1994; Kilian et al., 2011; Herwegh et al., 2014). However, the exact modes by which these domains are established are still poorly understood and the subject of intense research. 

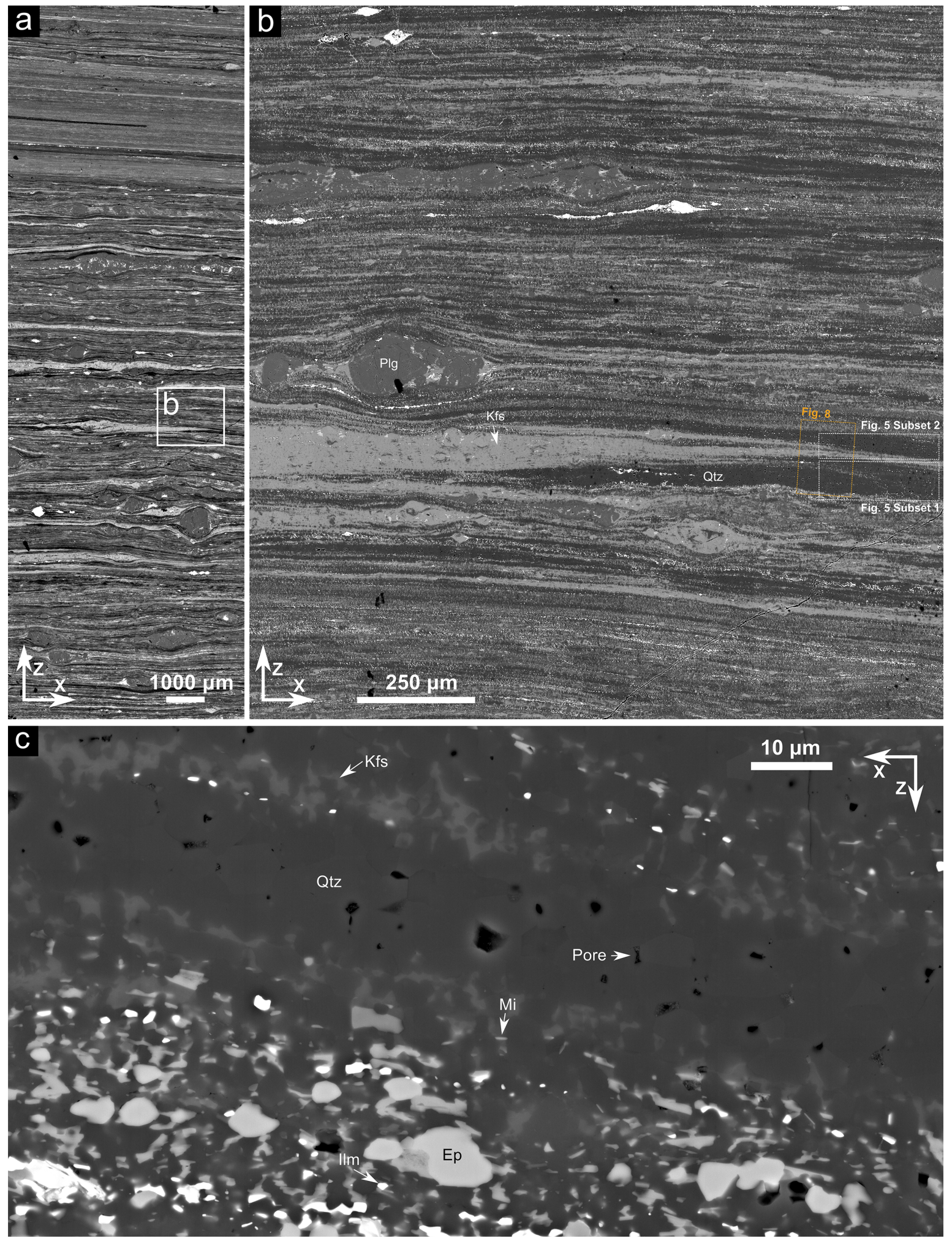

Figure 1. BSE images from the quartzo-feldspathic ultramylonite. Panel (a) shows the overall strain gradient in the sample, with the highest strain domain found at the top of the image. Panel (b) is a high-resolution BSE SEM mosaic of a representative area of the sample $(41448 \times 40282$ pixels, scale of 1 px : $35.5 \mathrm{~nm})$. All results presented for pore shape and orientation analysis are from the area of Fig. $1 \mathrm{~b}$. The greyscale values identify minerals as follows: black: porosity, dark grey: Qtz, grey: Plg, light grey: Kfs, bright: accessory phases. Panel (c) presents the edge of a disaggregating quartz domain and highlights the minerals present in the poorly mixed polyphase domains. 
One of the details under investigation is the role of fluids and their pathways. Models have been proposed for brittle-fracture-based pumping and the advection of fluids (Etheridge et al., 1984), diffusion-dominated granular flow (Paterson, 1995) and more recently a dynamic granular fluid pump that is dominated by fluid advection (Fusseis et al., 2009). Fusseis et al. (2009) postulated that in ultramylonites, fine-grained polyphase domains deforming by viscous grainboundary sliding (VGBS) develop the dynamic granular fluid pump. This pump operates during deformation and utilises a synkinematic porosity known as creep cavitation. Here, creep cavitation is defined as a porosity that results from entropy production during deformation. A stringent consequence of this definition is that pore nucleation must arise directly from the active deformation mechanism's response to the shortening and stretching of the rock mass. It is clear that a model generating fluid pathways in the middle crust that does not require brittle fracturing has significant implications for the controls of the exchange of fluids between the hydrostatic and lithostatic pore fluid pressure regimes (Ingebritsen and Manning, 2010), phase nucleation in mylonites (Kruse and Stünitz, 1999) and, by extension, rheology.

The phenomenon of creep cavitation has been well described in material science, with several distinct types of creep cavitation being distinguished (Riedel, 1987). To date, geological research has identified evidence for creep cavitation in natural ultramylonites from the middle crust (Behrmann and Mainprice, 1987; Mancktelow et al., 1998; Herwegh and Jenni, 2001; Fusseis et al., 2009; Kilian et al., 2011; Rogowitz et al., 2016), the lower crust (Závada et al., 2007; Menegon et al., 2015) and in mantle rocks (Rovetta et al., 1986; Précigout et al., 2017). Experimental work has shown that octachloropropane, quartzite, diabase, feldspar aggregates, anorthite-diopside aggregates, olivineclinopyroxene aggregates and calcite-muscovite aggregates can develop creep cavities (Caristan, 1982; Hirth and Tullis, 1989; Ree, 1994; Dimanov et al., 2007; Rybacki et al., 2008; Delle Piane et al., 2009; Précigout and Stünitz, 2016). This dataset is small but diverse and suggests that creep cavities can occur in many types of deforming rocks across varying pressure, temperature and rate conditions.

The wide variety of metamorphic conditions at which cavities form suggests that a range of micro-scale processes contribute to creep cavitation. Many of the geological works cited interpret creep cavities as the product of VGBS that form to accommodate strain incompatibilities (Behrmann and Mainprice, 1987; Ree, 1994; Herwegh and Jenni, 2001; Dimanov et al., 2007; Závada et al., 2007; Rybacki et al., 2008; Fusseis et al., 2009; Kilian et al., 2011; Menegon et al., 2015; Précigout and Stünitz, 2016). In the VGBSbased model of Fusseis et al. (2009), cavitation at one grain triple junction is balanced by cavity closure at other grain triple junctions. This dynamic model of cavity formation is limited to domains deforming by some form of diffusion creep and does not account for all reports of creep cavities in geology. In other studies, creep cavitation was linked to the production of crystal defects (Wong, 1990; Rogowitz et al., 2016). It is unclear how these mechanisms relate to each other across rock types or if it is possible for multiple cavitation mechanisms to be active simultaneously.

Despite a growing body of observations on creep cavitation in rocks, some important open questions remain, including the following.

i. How do creep cavities effect an evolving rock rheology and how does this ultimately influence rock deformation?

ii. How ubiquitous are creep cavities in deformed rocks and what combinations of deformational processes facilitate their formation?

This contribution addresses the first question by examining in detail the nature and occurrence of creep cavities in a mid-crustal ultramylonite from the Redbank Shear Zone (Australia) and furthers our understanding of the second question. We use a sophisticated workflow combining electron microscopy, image analysis, electron backscatter diffraction (EBSD) and synchrotron-based x-ray nanotomography (nCT) to show that creep cavities can form by multiple mechanisms in one sample. We present a high-resolution map of porosity distribution on the millimetre scale in an ultramylonite and demonstrate how this porosity evolved during mylonitic deformation.

\section{Geological setting and sample description}

The Redbank Shear Zone (RBSZ) is part of a crustal-scale thrust duplex that formed during the Alice Springs orogeny in Central Australia (Teyssier, 1985b). Due to its geometry, where higher-grade shear zones piggy-backed on lowergrade shear zones, the RBSZ has experienced no significant retrograde metamorphic overprint during its exhumation, and the synkinematic mineral fabrics and parageneses are preserved (Fliervoet et al., 1997). Micro-fabrics in the RBSZ are therefore ideal for the investigation of transient chemophysical processes that characterise mid-crustal shear zones.

The RBSZ is a network of shear zones that cascades across scales, with shear zone thicknesses that range from $10^{-3}$ to $10^{1} \mathrm{~m}$ displaying a characteristic protomylonite mylonite - ultramylonite succession (Teyssier, 1985a). This contribution focusses on a quartzo-feldspathic ultramylonite sampled from the amphibolite facies shear zones in the Black Hill area of the RBSZ (sample BH02; $23^{\circ} 32^{\prime} 46.81^{\prime \prime} \mathrm{S}$, $133^{\circ} 25^{\prime} 14.42^{\prime \prime} \mathrm{E}$; temperature $350-550^{\circ} \mathrm{C}$; lithostatic pressure $500 \mathrm{MPa}$; Fliervoet et al., 1997). The sample is a banded ultramylonite that displays a striking and extensive grainboundary porosity that is hosted in fine-grained $(\sim<20 \mu \mathrm{m})$, monomineralic quartz bands (Fig. 1). In addition, the sample shows thick domains of well-mixed polyphase material and a network of fine-grained $(\sim 1-2 \mu \mathrm{m})$ polyphase 
layers that envelop large, fractured augen porphyroclasts $(\sim 1 \mathrm{~mm})$. In general, the sample's foliation is defined by the monomineralic quartz bands and the thicker polyphase domains, whereby the quartz bands display no signs of boudinage. This work focusses on the microstructure of the quartz bands and the nature of the porosity they host. We interpret the disaggregating quartz domains at different stages of dispersal (cf. Kilian et al., 2011) to offer an insight into the locally evolving quartz micro-fabric and an associated porosity.

\section{Methods}

\subsection{Sample preparation}

We analysed a small sample block, which was cut parallel to the stretching lineation and perpendicular to the foliation (long- and short-axis dimensions of sample: $22.9 \times 19.4 \mathrm{~mm}$ ) and then polished and carbon coated (thickness $\sim 20 \mathrm{~nm}$ ) for electron microscopy and EBSD. To split the sample along the mylonitic foliation (after electron microscopy), it was pre-cut parallel to the stretching lineation and cleaved in a vice. The split surface was gold coated (thickness $\sim 3 \mathrm{~nm}$ ).

\subsection{Data acquisition and processing}

\subsection{Microstructural analysis}

A large $(41448 \times 40282$ pixels on a scale of $1: 35.5$; $\mathrm{px}: \mathrm{nm}$ ) backscatter electron (BSE) map was acquired on an FEI Quanta FEG 650 SEM operated at an accelerating voltage of $20 \mathrm{kV}$. This map was stitched from individual images using the Maps software by FEI.

\subsubsection{Image analysis}

The BSE map formed the basis of a detailed analysis of porosity. In BSE images, pores appear black. They were segmented using binary thresholding and labelled in Fiji (Schindelin et al., 2012) after a pre-processing workflow was applied to reduce noise (see the Supplement). Data were visualised with Matplotlib Python libraries (Hunter, 2007). Hexbin plots were used to help visualise large data scatter plots. A hexbin plot works by laying a hexagon grid over the data and then preforming a chosen operation on the data within the bounds of each hexagon. An example of operations that can be performed on data within a hexagon include count, sum and calculation of the mean. The kernel density for point features in the ESRI ArcGIS v10.1 software was used in pore cluster analysis for Fig. 2. The kernel smoothing factor was automatically calculated with reference to the population size and the extent of analysis and contoured based on a $1 / 4 \sigma$ kernel. For Fig. 5 kernel density calculations were made using the SciPy (Jones et al., 2001) and NumPy (van der Walt et al., 2011) Python libraries (see the Supplement for parameters used).
From the segmented data, the following parameters were evaluated.

- Pore size.

Defined as the cross-sectional area (in $\mu \mathrm{m}^{2}$ ) of a pore.

\section{- Pore orientation.}

Pore orientations were determined by using the long axis of the best-fit ellipse and calculating its deviation from the vertical axis of images shown. For ease of viewing, the orientation measures were folded along their symmetry axis, $90^{\circ}$, and presented as the value $\beta$. For example, $\beta=0^{\circ}$ describes a long axis aligned parallel to the vertical axis of the image analysed (and orthogonal to the mylonitic foliation in Fig. 1) and $\beta=90^{\circ}$ would be orthogonal to this (and parallel to the mylonitic foliation).

- Pore shape descriptions.

$$
\text { Circularity }=\frac{4 \pi(\text { Pore area })}{(\text { Pore perimeter })^{2}}
$$

Circularity is a shape descriptor that quantifies the complexity of a shape by linking the area and perimeter. It is important to note that circularity values are not unique but simply describe a deviation in shape from the area and perimeter relationship of a circle. A circularity value of 1 describes such a circle and decreasing values can represent either an increase in shape complexity (e.g. a star) or shape elongation or a combination of both (Cox, 1927).

$$
\text { Roundness }=\frac{4(\text { Pore area })}{\pi{\text { (Major axis })^{2}}^{2}}
$$

Roundness is a shape descriptor that only quantifies elongation. Used together, circularity and roundness can characterise pore shape complexity and elongation more correctly (Schindelin et al., 2012).

\subsection{Electron backscatter diffraction, EBSD}

EBSD data were collected at the University of Bern on a Zeiss Evo 50 SEM equipped with a Digiview II camera. The sample was tilted to $70^{\circ}$, and a $20 \mathrm{kV}$ accelerating voltage was applied (beam current was $\approx 2.5 \mathrm{nA}$, working distance $\approx 11.5 \mathrm{~mm}$ ). Crystallographic orientation data were obtained with a $0.65 \mu \mathrm{m}$ step size from automatically indexed EBSD patterns in TSL OIM. EBSD data were processed and plotted with MTEX (Mainprice et al., 2011). Raw data points with a $<0.1$ confidence index $(\mathrm{CI})$ and calculated grains with $<10$ indexed points in total were excluded from analysis. Orientation distribution functions (ODFs) calculated for pole figures use a kernel half-width of $7^{\circ}$, while ODFs calculated for misorientation angle histograms use a kernel half-width of $5^{\circ}$. 

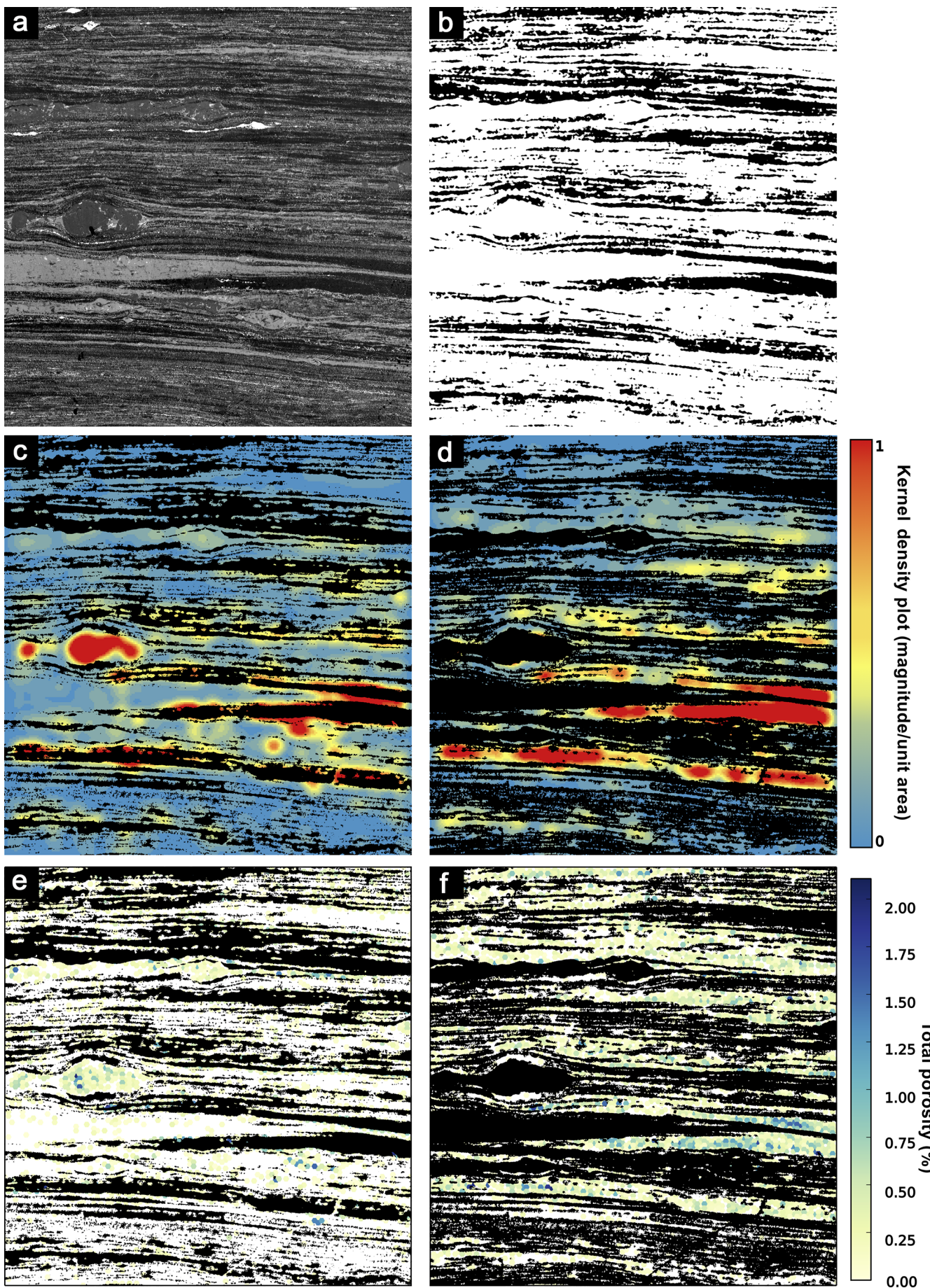

Figure 2. The spatial distribution of porosity in Fig. 1b. In the BSE mosaic of Fig. 1b, 8129 individual pores were identified. For reference, panel (a) displays the micro-fabric of the area analysed. Panel (b) is the mask used for distinguishing microstructural domains for analysis: quartz is coloured black. Panels (c, d) present masked kernel density analysis highlighting regions of pore clustering. Panel (c) is masked to remove all quartz and panel (d) is masked to only show the quartz. The clustering of pores is most prevalent in the thickest, most coherent quartz domains and in the largest feldspar porphyroclasts. Panels (e, f) are hexbin plots that are coloured to show the absolute porosity per hexbin, masked in the same fashion as panels $(\mathbf{c}, \mathbf{d})$. See Table 1 for porosity values per domain. 


\subsection{Split sample}

Broken surfaces explored in the SEM provide insight into pore morphologies and evidence for the redistribution of material (cf. Mancktelow et al., 1998; Fusseis et al., 2009). Images from the split sample were acquired on a Carl Zeiss SIGMA HD VP FEG-SEM using a $20 \mathrm{kV}$ accelerating voltage and $\mathrm{a} \sim 6.5 \mathrm{~mm}$ working distance. Oxford AZtecEnergy energy dispersive $\mathrm{x}$-ray (EDX) analysis was conducted at an aperture setting of $60 \mu \mathrm{m}$ and used to qualitatively evaluate phase compositions on the split surface. This form of mineral identification was necessary to interpret individual pores in their microstructural context.

\subsection{X-ray nanotomography}

We used an Xradia synchrotron-based nanotomograph at the Advanced Photon Source (beam line APS/32-ID) to acquire 3-D nanotomographic datasets of porous ultramylonitic quartz ribbon bands and assess the potential interconnectivity of pores. A cylindrical sample $(20 \mu \mathrm{m}$ diameter $\times 100 \mu \mathrm{m}$ length) was extracted using focussed ion beam techniques from a polished thin section that was cut from the sample. In the tomograph, radiographic projections were acquired over a rotation of $180^{\circ}$ at an $8 \mathrm{keV}$ beam energy and reconstructed to yield a 3-D nanotomographic dataset with a spatial resolution on the order of $70 \mathrm{~nm}$. Porosity was segmented with binary thresholding and labelled in Avizo Fire. Due to the small sample size and the noisiness of the data, no quantitative analysis was attempted. Volumetric data were visualised in Avizo.

\section{Result}

\subsection{Micro-fabric domains}

The investigated high-strain micro-fabric is composed of four microstructural components (Fig. 1).

1. Monomineralic quartz domains are elongated parallel to the foliation, exhibiting a varying degree of coherency as domains. Here coherency is used in the context of the spatial distribution of quartz grains to qualitatively describe the degree to which quartz grains are aggregated into monomineralic bands vs. dispersed into segregated grains. The most coherent quartz domains wrap around porphyroclasts and in some cases mantled porphyroclasts. The fringes of the thickest quartz domains show evidence for the removal of individual quartz grains and their progressive assimilation into neighbouring, poorly mixed polyphase domains. We assume that thinner quartz domains have advanced further on the path of disaggregating and that the progression from thicker to thinner quartz domains reflects a progressive microstructural evolution. This assumption does not pre- suppose that all thin quartz domains were once very thick, but we consider it highly unlikely that any thin quartz ribbon was initially just one or two grains wide (of a 10-20 $\mu \mathrm{m}$ diameter; Fig. 1).

2. Porosity that can be considered tri-modal: pores on quartz grain boundaries, pores hosted within porphyroclasts and cracks that cross-cut and run parallel to the foliation. Feldspar porphyroclasts host an intracrystalline, angular porosity which is distinctly different from the inter-crystalline porosity observed in association with quartz (see detailed discussion below).

3. Well-mixed and poorly mixed polyphase domains: the finest-grained $(<1-2 \mu \mathrm{m})$ parts of the ultramylonite make up the well-mixed polyphase domains (see lefthand side of Fig. 1a). There are also less well-mixed polyphase domains which contain disaggregated quartz $(<10 \mu \mathrm{m}$; Fig. $1 \mathrm{~b}$ and $\mathrm{c})$. The polyphase domains is comprised of plagioclase, K-feldspar, mica, epidote, ilmenite and quartz (Fig. 1c).

4. Porphyroclasts, which are generally either sodic plagioclase or K-feldspar. The K-feldspar porphyroclasts occasionally display flame perthites. Sodic oligoclase plagioclase porphyroclasts exhibit what appears to be a reaction to the fine-grained mantles of K-feldspar and mica (Fig. 1). No quartz porphyroclasts are observed.

\subsection{Image analysis in the $X Z$ plane of finite strain}

Pores were analysed in a representative area $\left(2.1 \mathrm{~mm}^{2}\right)$ of the sample. Figure $1 \mathrm{~b}$ shows the full extent of the area used for both spatial and pore shape analysis. Areas for subset analysis are also marked in Fig. 1b. Pores in all domains were extracted and considered in bulk for density analysis. Subsequently, masks were applied to quantify total porosity and analyse pore shapes in quartz domains separate from porphyroclasts and the polyphase domains. Pores in porphyroclasts and the fine-grained polyphase domains were analysed together.

\subsubsection{Spatial distributions of pores}

Kernel density analysis demonstrates that the porosity is anisotropically distributed, with a bimodal clustering in respect to domains (Fig. 2c and d). The majority of observable pores $(86 \%)$ exist in direct spatial association with quartz ribbon bands. In quartz domains, the highest density is recorded in the thickest, most coherent ribbons. In the porphyroclast and polyphase domains, the larger feldspar porphyroclasts that have seen the least fracture or reaction to smaller components show the highest density of pores. The total porosity measured in the area shown in Fig. 2e and $\mathrm{f}$ is presented in Table 1. 


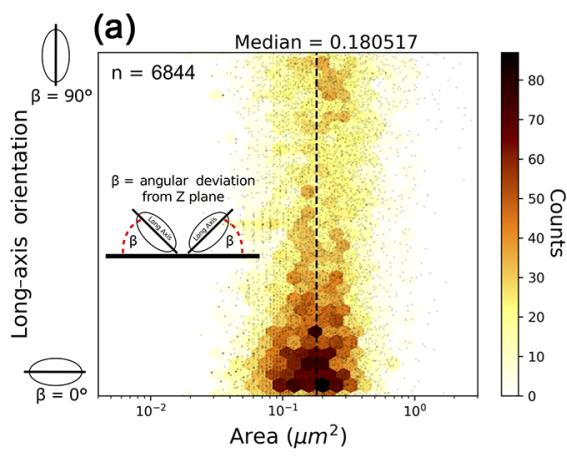

(b)

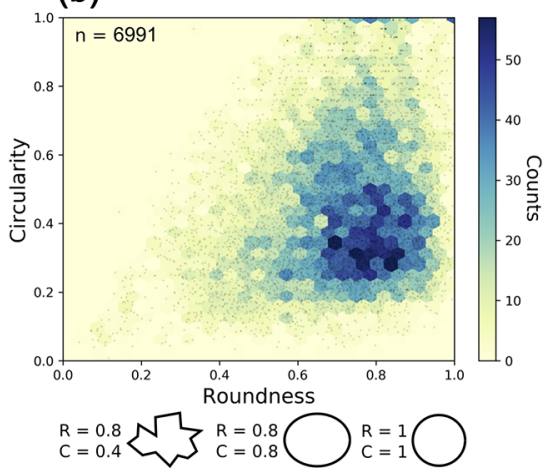

(c)

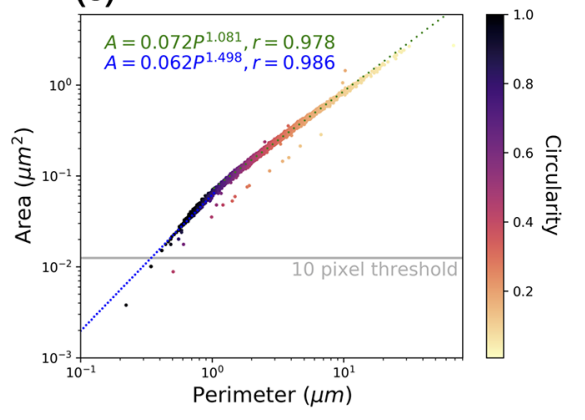

Figure 3. Plots of relationships for pore shape, size and orientation for all pores observed in association with the quartz domains of Fig. 1b. Due to the large sample size, pertinent clustering in data is more clearly observed when presented in hexbin plots (actual data points are overlain). In Fig. 3a and b, the hexbin plot colouring displays the number of data points contained within each hexbin. Panel (a) presents area as a function of pore long-axis orientation $\left(\beta=0^{\circ}\right.$ is parallel to the $Z$ plane of finite strain and $\beta=90^{\circ}$ is parallel to the $X$ plane of finite strain). Circular pores (circ $=1)$ are excluded from panel (a) because the long of a circle will not have a unique or meaningful orientation. Panel (b) compares each pore's circularity with its roundness. One large cluster $(\mathrm{circ}=0.3$, round $=0.8)$ and two minor clusters $($ circ $=1$, round $=1$; circ $=1$, round $=0.8$ ) are observed. Panel $(\mathbf{c})$ shows the relationship of pore perimeter with increasing cross-sectional area. Each data point is additionally coloured for its circularity. Two power-law trends are identified in panel (c). See text for further discussion.

Table 1. Porosity data from Fig. 2.

\begin{tabular}{lrrrr}
\hline Domain & $\begin{array}{r}\text { Number of pores } \\
\text { in domain }\end{array}$ & $\begin{array}{r}\% \text { of total } \\
\text { porosity }(\%)\end{array}$ & $\begin{array}{r}\text { Absolute porosity } \\
\left(\mu \mathrm{m}^{2}\right)\end{array}$ & $\begin{array}{r}\text { Porosity presented } \\
\text { as \% of total area } \\
\text { of Fig. 1b (\%) }\end{array}$ \\
\hline Quartz & 6991 & 86 & 1515 & 0.07 \\
Porphyroclast + polyphase & 1138 & 14 & 247 & 0.01 \\
\hline
\end{tabular}

\subsubsection{Pores in monomineralic quartz}

Segmented pores were analysed to identify any systematic changes in pore size, shape and orientation. Figures 3 and 4 show the analysis for the area shown in Fig. 1b, while Fig. 5 shows the subset analyses.

\subsubsection{Pore sizes}

It can be seen that pores cover a limited range of values in cross-sectional area (focussed strongly around a median value of $0.18 \mu \mathrm{m}^{2}$ ) but vary greatly in long-axis orientation (Fig. 3a). The lower limit of pore area may be controlled by the resolution of the imaging technique. At first inspection there are two maxima in Fig. 3a: pores with a low $\beta$ and pores with a high $\beta$. The maximum for low $\beta$ values appears to be more significant.

\subsubsection{Pore shapes}

As stated above, a pore's shape complexity and elongation can be characterised by combining circularity and roundness. When circularity is plotted against roundness, three salient clusters are observed (Fig. 3b):
1 . pores with a circular character (circularity $\approx 1$, roundness $\approx 1)$

2. pores with an elliptic character (circularity $\approx 1$, roundness $\approx 0.8$ );

3. and pores with a complex shape but only moderate elongation (circularity $\approx 0.3$, roundness $\approx 0.8$ ).

Figure $3 \mathrm{c}$ shows that when area is plotted against perimeter and coloured for circularity, there are some systematics that can be described by two power-law relationships.

Area $=0.062 \cdot$ Perimeter $^{1.498}$
Area $=0.072 \cdot$ Perimeter $^{1.081}$

We assign pores described by these equations to two distinct populations. From Fig. 3, it is evident that the pores characterised by Eq. (3) have very high circularity. Furthermore, Fig. $3 \mathrm{~b}$ and c suggest that the very circular pores are the smallest (in cross-sectional area). These small, circular pores are then linked by Eq. (3) to the elliptical pores (elliptical pores having a circularity $\approx 0.8$ and roundness $\approx 0.8$ ). This relation can be most clearly seen in Fig. 3c, in which 

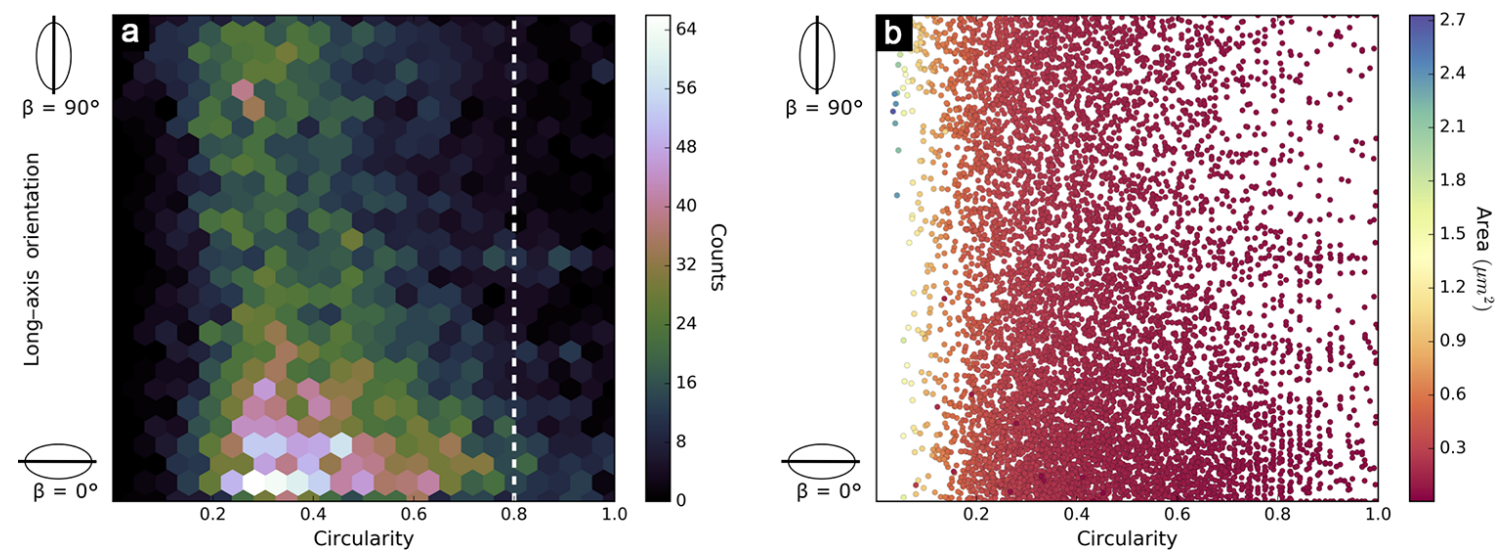

Figure 4. The link between pore orientations, pore sizes and their shapes in detail. Figure 4 presents only data for pores with circularity values $<1$. A delineation ( $\mathrm{circ}=0.8)$ is presented to show the change in power-law relations observed in Fig. $3 \mathrm{c}$. Panel (a) shows that with decreasing circularity there is an increase in the variability of $\beta$ values. Panel (b) presents the same data as Fig. 4a but with the data points coloured for cross-sectional area. The largest pores are observed to mostly have high $\beta$ values.
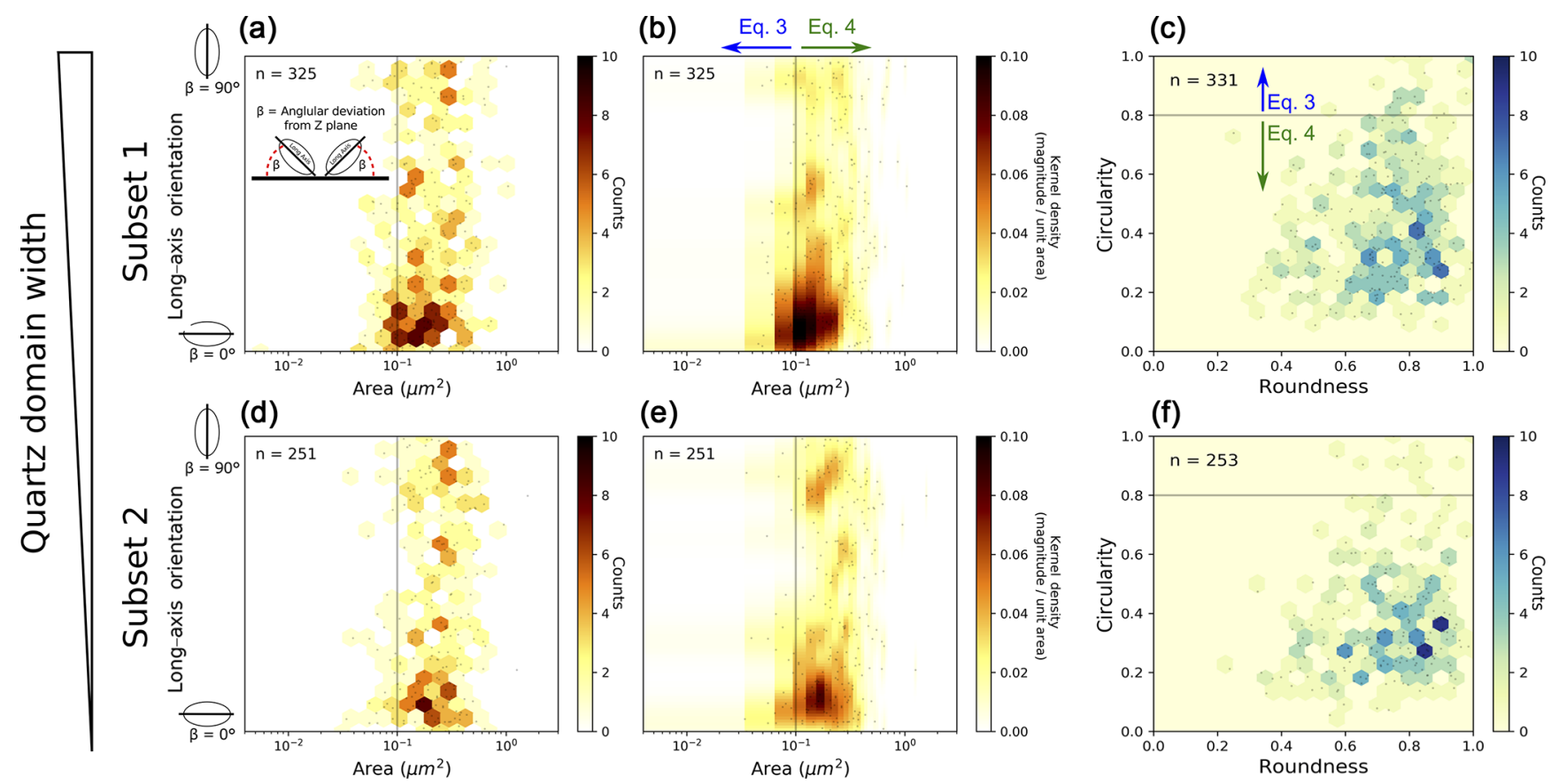

(e)

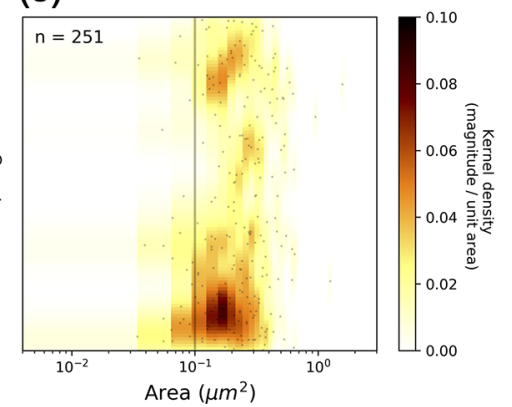

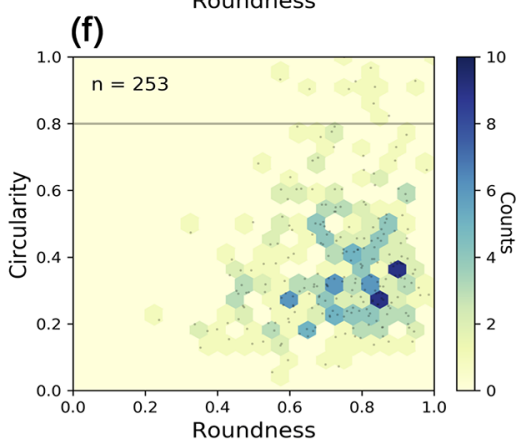

Figure 5. Pore analyses for subsets 1 and 2 shown in Fig. 1b corresponding to decreasing quartz domain width and increasing quartz dispersion. Lines marking the change in pore shape relations described by Eqs. (3) and (4) are presented in each plot. Panels (a, d) present pore long-axis orientation against pore area data in hexbin plots, while panels (b) and (e) show the same data but with true point density analysis. Both sets of figures show that with decreasing quartz band thickness, there is an increase in the range of pore orientations observed. Panels (c) and (f) demonstrate that this change is also concordant with a change in the pore shapes from roughly elliptical to more complex. More specifically, it can be seen in panels (b) and (d) that with decreasing domain width there is a loss of circular and elliptical pores.

Eq. (3) describes pores of a circularity ranging from 1 to $\approx 0.75$. Similarly, Eq. (4) suggests that all pores with circularity values below $\sim 0.8$ are systematically linked and scale in shape with a power-law relationship.

\subsubsection{Changes in pore orientations}

We assume that the long axis of a pore's best-fit ellipse is roughly parallel to the orientation of the pore's boundary with the host minerals and therefore representative of pore orientation. For pores with a circularity less than 1, the Feret diameter is seen to have the same orientation as the long axis 
of the best-fit ellipse (see the Supplement Fig. S1). Figure 3a shows a variation in pore orientations but does not readily highlight any systematics. However, if Fig. 3a is considered with Fig. 3c, it can be seen that pores whose shape is governed by Eq. (3) generally have a lower value of $\beta$ (see pores with areas $\sim \leq 0.1 \mu \mathrm{m}^{2}$ ). Figure 4 decomposes this observation to clearly show that the orientations of the more circular pores $(>0.8)$ rarely exceed $45^{\circ}$ and predominately assume a low angle to the $Z$ direction of finite strain (Fig. 4a). The change in pore orientation at a circularity of 0.8 corresponds to the change in the equation governing pore shape (see Fig. 3c). There is also a clear propensity for the largest, least circular pores $\left(>2 \mu \mathrm{m}^{2}\right)$ to be oriented more parallel to the shear plane (Fig. 4b). It is unclear if these largest pores are foliation parallel cracks that post-date deformation.

\subsubsection{Porosity with a changing quartz microstructure}

Spatial analysis of pore occurrences has already shown that pore density decreases with quartz domain thickness (Fig. 2d). In combination with microstructural evidence for the disaggregation of quartz domains, it is possible to consider the evolution of porosity congruent with that of quartz domains (Fig. 5). It can be observed that the pore shape descriptors change with the quartz microstructure. Firstly, in the thicker quartz domain, both pore populations (described in Eqs. 3 and 4) are observed (Fig. 5c). In this domain, pores generally have their long axes aligned with the $Z$ direction of finite strain (Fig. 5a and b). However, both the pore population and orientation change as quartz domains become thinner. It can be seen that in the thinner quartz domain there is an absence of pores from the trend described by Eq. (3) (Fig. 5f) and that pore orientations become far more variable (Fig. 5d and e).

\subsection{Observations of pores in the $X Y$ plane of finite strain}

\subsubsection{Pore shapes and orientations}

On the broken surface, the porosity present in the thickest quartz domains shows a clear preference to occur along grain boundaries roughly parallel to the $Y Z$ plane (Fig. 6a). When the pore morphology is considered with respect to the grainboundary arrangement at the pore location, two end-member shapes can be identified. Firstly, there are roughly elliptical pores in the $Y Z$ plane. These pores can either show an asymmetry, truncating on a flat grain boundary (e.g. uppermost white arrow in Fig. 6a), or be symmetrical about the grain boundary (e.g. smaller pore in Fig. 6b). Secondly, there is an occurrence of angular pores at quartz grain triple junctions (see all yellow arrows in Fig. 6).

\subsubsection{Precipitates on grain boundaries}

The broken surface also reveals information about material redistribution in spatial association with the porosity in the quartz directly surrounding a plagioclase porphyroclast. The porphyroclast itself shows reaction to more K-rich material, which appears to have a flakey morphology (see the area highlighted as Kfs in Fig. 6c). In contrast, nearby quartz grain boundaries are covered in a dendritic material (see lower left-hand side of Fig. 6c). The EDX conducted on the broken surface showed the chemistry of the dendrites to be $\mathrm{Si}$ rich, with no other obvious chemical signal. Sharply truncated dendrites (see blue arrow in Fig. 6c) seem to preferentially occur on dilatant quartz grain boundaries. Figure $6 \mathrm{~d}$ highlights textural evidence linking crystallite precipitation (empty blue arrow in Fig. 6d) and a dendrite on a dilatant grain boundary (filled blue arrow in Fig. 6d). It is noteworthy that very little evidence for the dissolution of quartz can be found. Etch pits were observed only on one site (Fig. 6d).

Interestingly, many pores appear empty, but some also seem filled with crystallites. With increasing distance from the porphyroclast there is a transition from the dendritic features on the dilatant grain boundaries to clusters of crystallites in pores and along grain boundaries (see all blue arrows in Fig. 6e). At the furthest distances from the porphyroclast in the quartz domain, only small amounts of very isolated crystallites are observed (Fig. 6b).

\subsection{Observations of pores in 3-D}

Due to a range of technical difficulties, $\mathrm{nCT}$ yielded only one dataset that provided insights into a porous quartz layer of about $50 \mu \mathrm{m}$ width. Figure 7 shows a visualisation of labelled pores and highlights interconnected creep cavities in three dimensions. The pores in this layer are mostly oblate and seem to occupy a range of orientations, mostly at high angles to the foliation (parallel to the top and bottom surfaces of the bounding frame). Most importantly, it is clear from Fig. 7 that pores are indeed interconnected and not constrained to the polished surface investigated in this study. We consider this proof that at most a small minority of pores observed in Fig. 1 are formed by plucking during sample preparation.

\subsection{EBSD analysis}

To better understand any potential link between the porosity and the mechanisms accommodating mylonitic deformation in quartz domains, EBSD analysis was undertaken. The results show clear evidence for crystal plastic processes with the presence of a crystallographic preferred orientation (CPO), subgrains and the occurrence of lattice distortions (Figs. 8 and 9). These crystal plastic processes are not uniform across the area analysed (Fig. 8b). It can be seen that the thicker quartz band hosts more features that are considered diagnostic of dislocation creep (Figs. $8 \mathrm{~b}$ and 9 subset 1 ). 


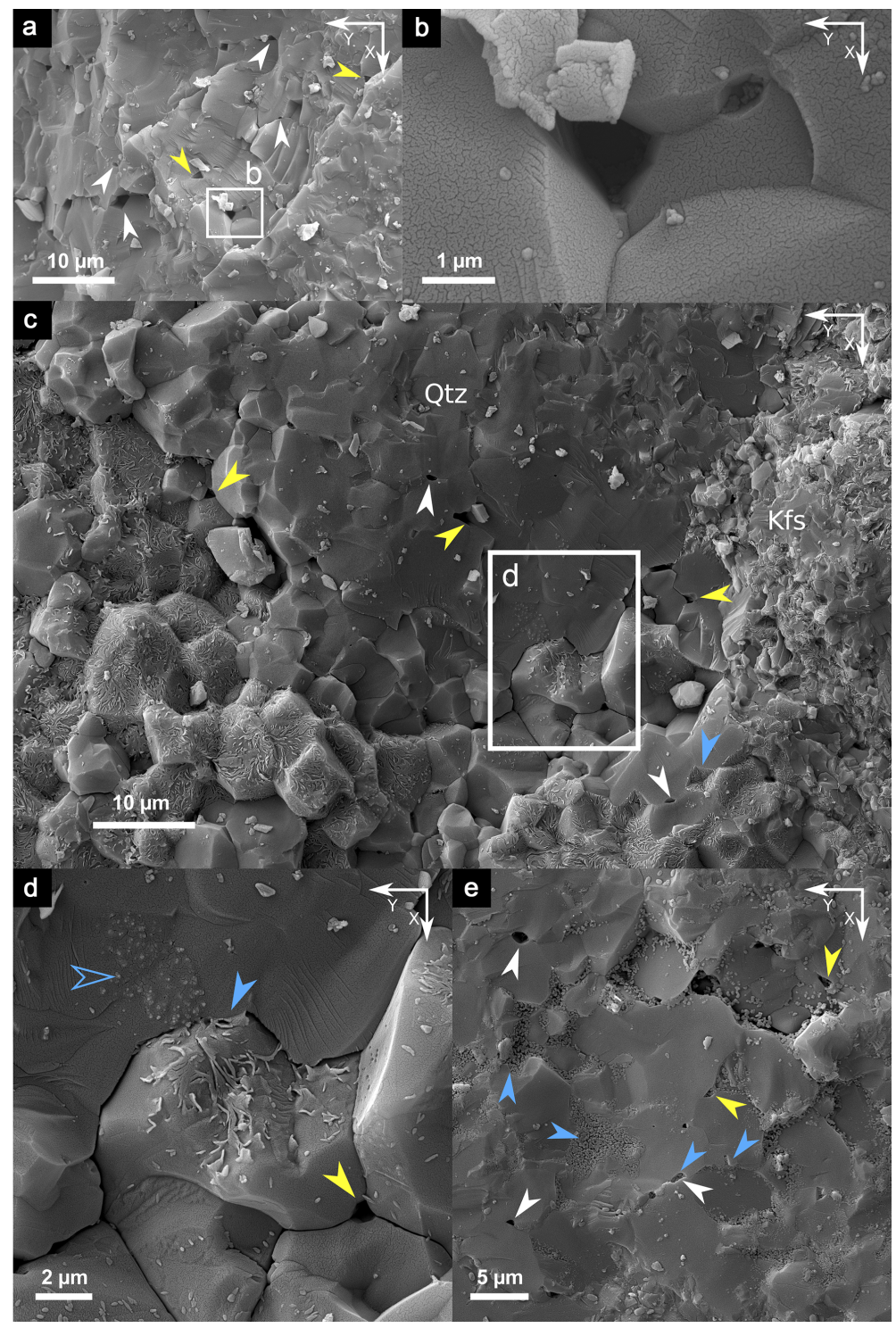

Figure 6. Secondary electron images from broken surfaces of quartz domains. White and yellow arrows point respectively to pores on grain boundaries with a low angle to the $Y Z$ plane of finite strain and to pores at grain-boundary trip junctions. Blue arrows highlight "precipitation" features, with the empty blue arrow in panel (d) identifying crystallites interpreted to be incipient precipitates found on a less dilatant grain boundary. Panel (a) shows a thick, coherent, monomineralic quartz domain that has an abundance of pores. Panel (b) highlights the difference between a pore found at a triple junction and a pore found in the middle of a grain boundary (see Fig. 1c for comparison in $X Z$ plane). Panels (c), (d) and (e) show the change in porosity and grain-boundary features with increasing distance from a plagioclase porphyroclast (see text for more detail).

These processes then become less well-articulated in the thinner quartz band (Figs. 8 b and 9 , subset 2). The abatement of lattice distortions and subgrains coincides with a reduction in grain size and texture strength. The loss of texture strength in the pole figures is further expressed in the misorientation angle distributions, with the thinner quartz band showing a nearly uniform distribution of misorientations (Fig. 9, subset 3$)$.

\section{Discussion}

\subsection{A model for synkinematic creep cavitation by different mechanisms}

Our study not only advances our understanding of porosity distribution in mid-crustal ultramylonites but also provides critical insight into the mechanisms behind synkinematic cavity formation and the associated effects on rock rheology. 


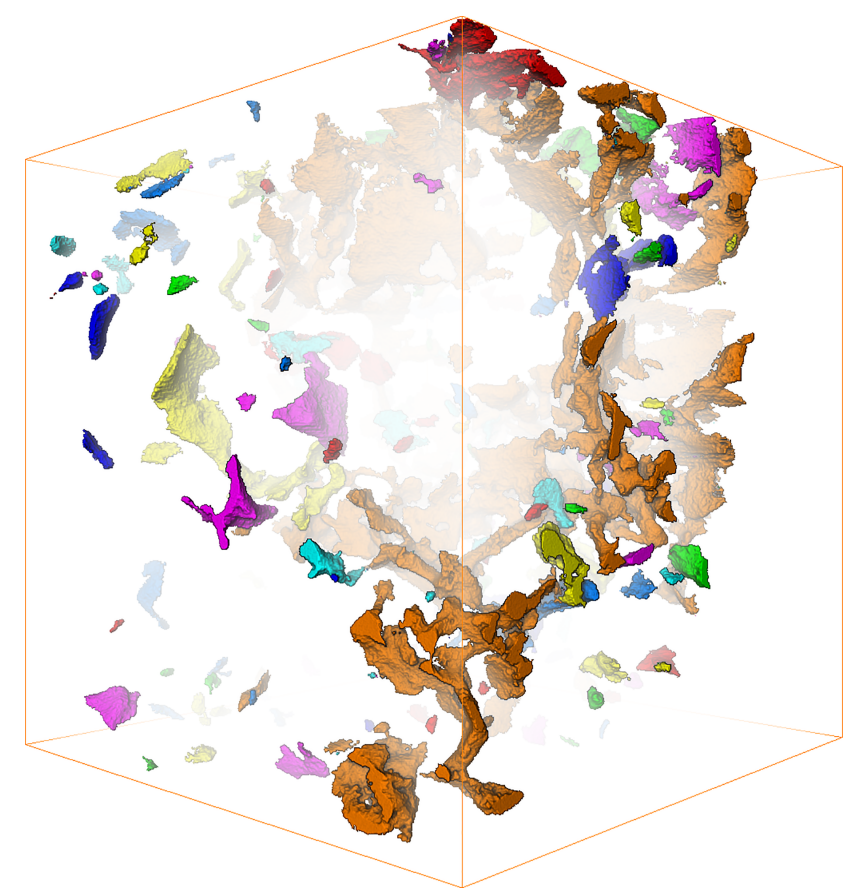

Figure 7. 3-D rendering of cavities segmented from a nanotomographic dataset. Pores are coloured individually to highlight connectivity. This means that a single colour allows for the tracing out of pore connections. For example, note the large interconnected pore cluster in orange. The dimension of the cube is $700 \mathrm{voxel}^{3}$, with a voxel size of $\sim 35 \mathrm{~nm}$. The top and base of the cube are parallel to the mylonitic foliation. The figure indicates the oblate shape of most cavities and proves that they are indeed 3-D features.

To develop this in detail, we interpret different quartz microstructures in our sample as representing different stages in a progressive evolution ("space for time"; see also Fusseis et al., 2006; Kilian et al., 2011). If the well-mixed polymineralic domains are the most mature parts of the studied ultramylonite, monomineralic quartz domains must be considered as relics of an original mylonitic fabric that has been captured in the process of disaggregation. The mechanisms of disaggregation can be observed at the jagged edges of monomineralic quartz domains and by comparison of thinner, less coherent quartz domains with thicker, more coherent ones. Our EBSD data from these domains suggest that during progressive disaggregation, quartz micro-fabrics with a clear CPO get randomised (Fig. 9). This is typically interpreted as indicating a transition from GSI creep to GSS creep accommodated by viscous grain-boundary sliding (Mitra, 1978; Etheridge and Wilkie, 1979; Kerrich et al., 1980; Behrmann and Mainprice, 1987; Závada et al., 2007; Kilian et al., 2011; Herwegh et al., 2014; Menegon et al., 2015; Viegas et al., 2016).

Our data show how a synkinematic porosity can be associated with this inferred change in rheology and the formation of a quartzo-feldspathic ultramylonitic micro-fabric.
In our sample, quartz domains are associated with an overt porosity and we consider the pores in the quartz domains to be creep cavities (Riedel, 1987). We claim that the cavities evolved synkinematically with both the microstructure and the dominant deformation mechanisms, finding that the disintegration of quartz domains is a result of the emergence of creep cavities. These creep cavities have two distinct populations and formed hierarchically. We integrate our findings in a model (Fig. 10) in which Zener-Stroh cracking produced small cavities in domains deforming by GSI creep (Fig. 10a, blue trend; Fig. 10b, time 1). We infer that their formation promoted fluid ingress, which in turn lowered the adhesion and cohesion of grain boundaries (cf. Billia et al., 2013). The addition of a fluid locally increased the contribution of VGBS to strain energy dissipation, which led to the formation of a second population of creep cavities (Fig. 10a, green trend; Fig. 10b, time 2) (Fusseis et al., 2009).

Image analysis constrained the two populations of creep cavities in detail (Fig. 3c).

i. Cavities with a perimeter smaller than about $\sim 2 \mu \mathrm{m}$ with long axes that have a low angle to the $Y Z$ plane of finite strain (Figs. 3c and 4a) and are governed by the power-law relation in Eq. (3).

ii. A population of larger cavities that has initially jagged or incised perimeters and generally elliptic shapes (Fig. $3 \mathrm{~b}$ and c). The long axes of these larger cavities exhibit a wider variation in orientation (Fig. 4a). However, the largest of these cavities tend to be aligned with grain boundaries that are parallel to the shear plane (Fig. 4b). This population is governed by the power-law relation in Eq. (4).

In our sample, thicker, more coherent quartz domains show more of the former population, and thinner, less coherent quartz domains contain only cavities with the latter characteristics (Fig. 5). It can also be observed that congruent with the change in cavity characteristics and domain width, there is a randomisation of the CPO present (Fig. 9). We interpret these observations to indicate that larger cavities are associated with VGBS.

Synkinematic creep cavitation by VGBS is not a new idea in geology: several microstructural (Behrmann and Mainprice, 1987; Herwegh and Jenni, 2001; Závada et al., 2007; Fusseis et al., 2009; Kilian et al., 2011; Menegon et al., 2015) and experimental works (Ree, 1994; Dimanov et al., 2007; Rybacki et al., 2008; Précigout and Stünitz, 2016) invoke the process. Experimental work by both Dimanov et al. (2007) and Rybacki et al. (2008) show that pores generated during deformation by VGBS have a complex, angular and elongated shape. This agrees well with our observations of increasingly disaggregated, thinner quartz domains (Fig. 5, subset 2) with their weakened CPO (Fig. 9, subset 2). As this type of cavity formation has been well discussed in previous contributions we will not examine this further. 


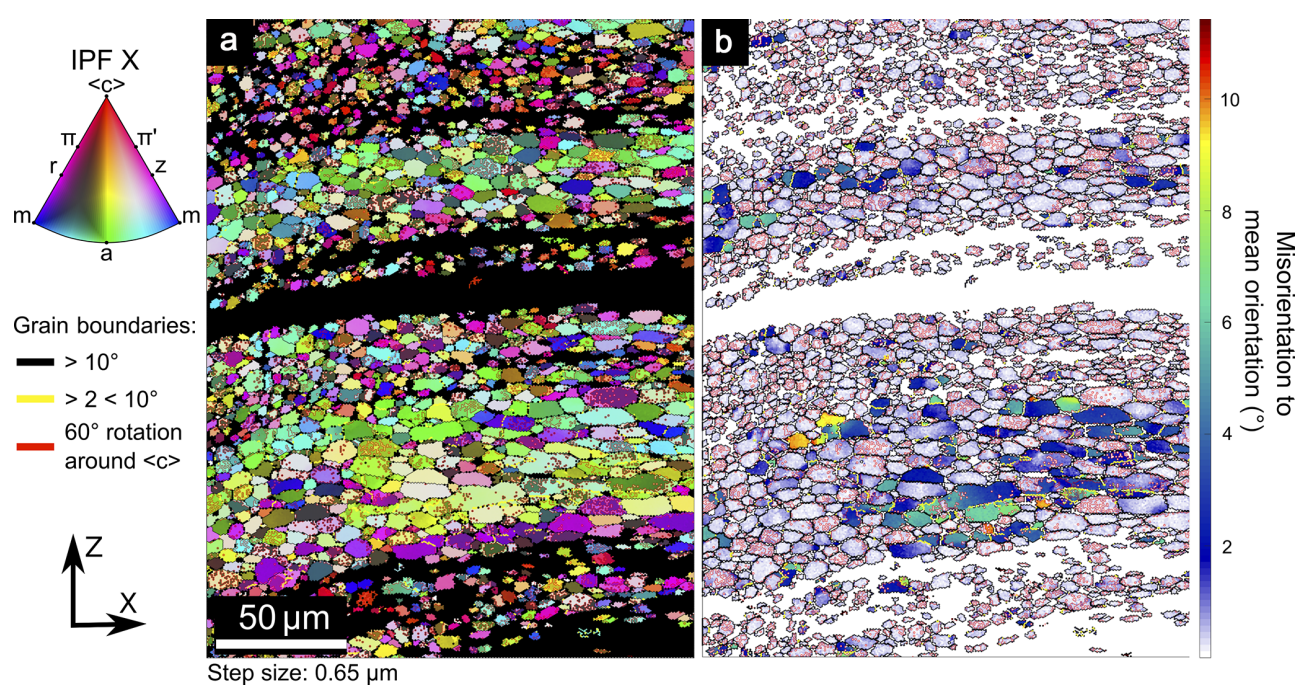

Figure 8. EBSD maps for the region of interest in Fig. 1b. Panel (a) shows an inverse pole figure map coloured for the $X$ direction of finite strain. Colours in panel (b) relate each pixel's orientation to the mean orientation of the grain that hosts the pixel.
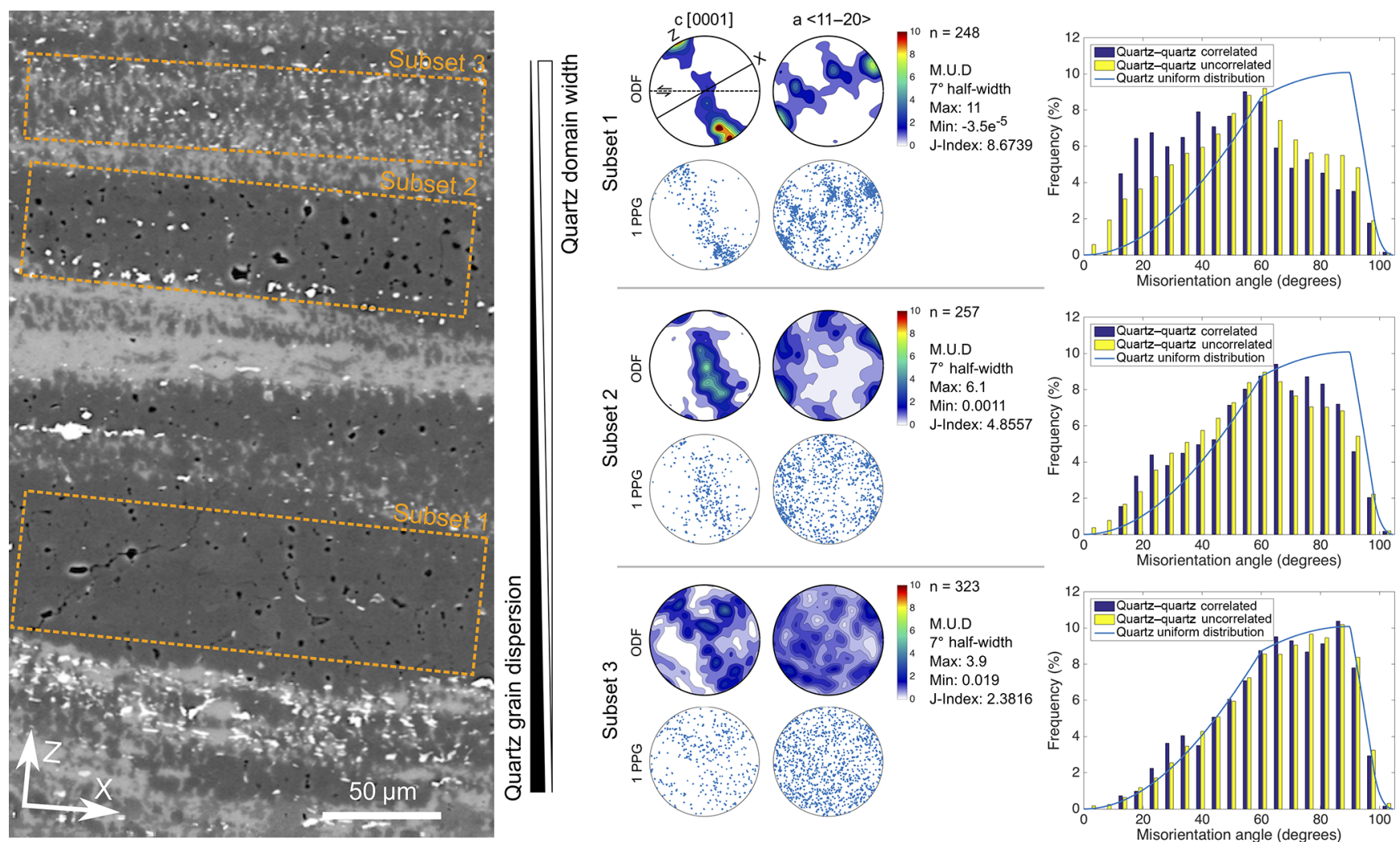

Figure 9. EBSD subset analyses of quartz domains. The EBSD analyses were preformed in the same quartz bands used for subset image analysis (see Figs. 1 and 5). EBSD data are presented in equivalent subsets corresponding to decreasing quartz domain width and increasing quartz dispersion. A clear CPO is observed in the pole figure analysis of subset 1 with two c[0001] maxima and two corresponding $a<11-$ $20>$ maxima. As quartz domain thickness decreases there is a randomisation of the CPO highlighted by the decrease in the $J$-Index and supported by the shift to a nearly random distribution of the misorientation angle histogram of subset 3 . Note that only grain-boundary data are presented in the misorientation angle histograms. Subgrains and Dauphine twin boundaries are excluded from the visualisation. 


\section{A model for hierarchical cavity formation}

(a)

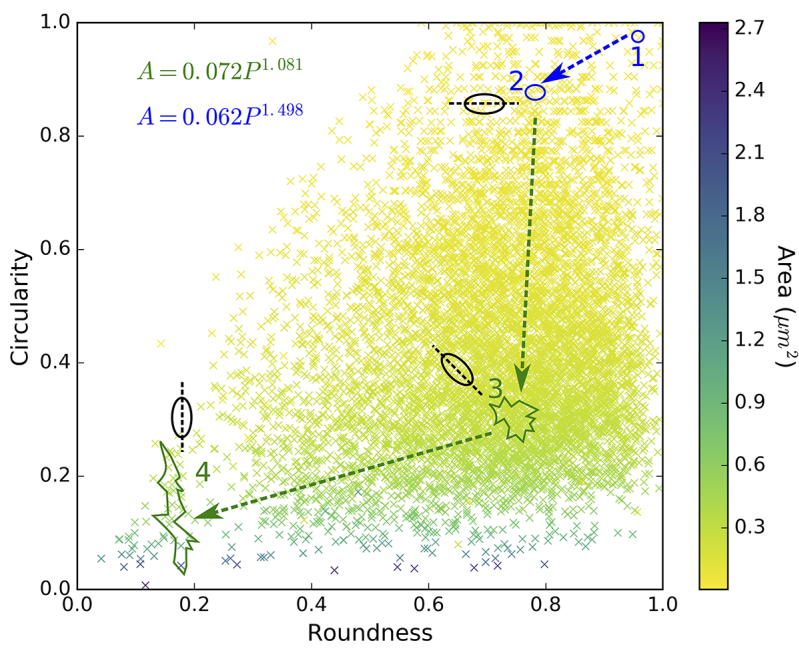

(b)
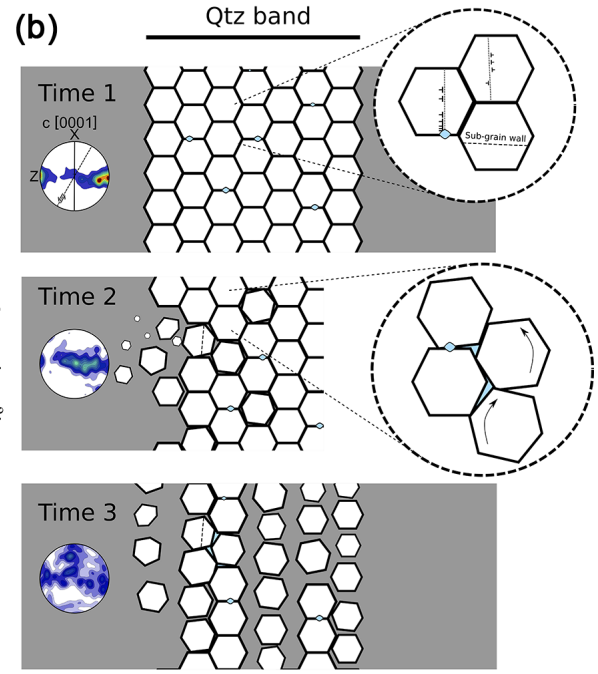

Figure 10. A model for synkinematic creep cavity formation by two different mechanisms. Panel (a) graphically represents the inferred trajectory of a creep cavity's life cycle. Initially creep cavities grow from circular (1) to elliptical cavities (2). These cavities generally have long axes aligned in the $Z$ direction (when viewed in the $X Z$ plane). As cavities become larger they develop more complex shapes and rotate (3), ultimately elongating and becoming more aligned with the shear plane (4). Panel (b) schematically integrates our observations of cavity evolution with the evolution of the microstructure and the associated micro-mechanisms. First cavities form in quartz domains deforming by GSI creep through the Zener-Stroh mechanism (b, time 1). As the grain-boundary strength is weakened by the ingress of fluids into cavities, VGBS is promoted. This increase in the contribution of VGBS drives the production of new creep cavities of a more complex shape (b, time 2). It is the production of creep cavities that initiates the increased contribution of VGBS and ultimately prompts a switch to a GSS creep. See text for details.

In contrast, geological descriptions of creep cavities that formed by Zener-Stroh cracking are still rare (Rogowitz et al., 2016). In the quartz domains of our sample that deformed dominantly by GSI creep, the population of very small cavities does not occur at grain triple junctions but rather seems to nucleate along grain boundaries that are aligned in the $Y Z$ plane of finite strain (Figs. 4a, 5, subset 1; Fig. 6, all white arrows). Boundaries in these orientations are mechanically unlikely to experience significant sliding, which suggests that VGBS is not conditional for cavity formation and alternative mechanisms might be relevant. In material science, it has been shown that creep cavities in an environment that is characterised by work hardening can nucleate by the coalescence of dislocations. This will occur where crystallographic slip bands intersect with grain boundaries or grain-boundary precipitates, allowing dislocations to pile up and thus forming Zener-Stroh cracks (Stroh, 1957; Bauer and Wilsdorf, 1973). On the basis of our observations we speculate that cavitation by Zener-Stroh cracking could have provided an initial porosity in monomineralic quartz domains that emerged directly out of GSI creep and potentially played an important role in the rheological evolution of the ultramylonite.

\subsection{Nucleation of creep cavities during GSI creep}

Despite evidence provided by cavity shapes and orientations (Figs. 3, 4, 5 and 6), unequivocal proof of Zener-Stroh cracking is difficult. For the Zener-Stroh mechanism to act, the material must have an abundance of crystal defects produced by deformational work (Stroh, 1957). In our sample, the presence of a CPO, subgrains and the occurrence of lattice distortions in the thick quartz domains are evidence for the activity of dislocation creep processes and hence the production of crystal defects in the same microstructural domains that host creep cavities. Our analysis further shows that the orientation of the dominant slip direction in these domains is aligned with the $X$ direction of finite strain (Fig. 9, subset 1). Grain boundaries at high angles to the $X$ direction (i.e. those in the $Y Z$ plane) could provide the obstacles required for dislocations to pile up, which could result in cavitation by Zener-Stroh cracking (Stroh, 1957). Evidence for quartz grain-boundary porosity in association with high dislocation density has been reported in previous studies of ultramylonites (Shigematsu et al., 2004; Behrmann, 1985; Rogowitz et al., 2016). Recently, Rogowitz et al. (2016) explicitly invoked the Zener-Stroh mechanism to explain small grain-boundary cavities next to dislocation pile-ups. In light of these studies and despite the fact that we can only pro- 
vide indirect evidence, its seems reasonable to speculate that the process of cavity nucleation could be that of Zener-Stroh cracking.

A dislocation-driven cavitation would require an appropriate density of dislocations to be present for a creep cavity to nucleate. It follows that cavity production consumes defects, and in this way it is a process that may directly compete with other recovery processes such as subgrain wall formation. Our SEM observations of cavities and subgrains suggests that both coexist. Kilian et al. (2011) has demonstrated the importance of subgrain wall formation in the disaggregation process of quartz domains in quartzo-feldspathic ultramylonites that have experienced similar geological conditions as those investigated here. From an irreversible thermodynamic perspective, integrating cavitation as a dissipative component of dislocation creep would expand our current understanding of a crystal's internal entropy production (see Eq. 1 of Huang et al., 2009). This would alter Eq. (18) of Huang et al. (2009), which describes the total rate of reduction $\left(\rho^{-}\right)$of the dislocation density at a steady state $(\rho)$. Integrating Zener-Stroh crack formation as a $\rho^{-}$mechanism would yield

$$
\frac{\mathrm{d} \rho^{-}}{\gamma}=\frac{\mathrm{d} \rho_{\mathrm{DRX}}^{-}}{\gamma}+\frac{\mathrm{d} \rho_{\mathrm{DRV}}^{-}}{\gamma}+\frac{\mathrm{d} \rho_{\mathrm{CAV}}^{-}}{\gamma}
$$

where $\frac{\mathrm{d} \rho_{\text {DRX }}^{-}}{\gamma}, \frac{\mathrm{d} \rho_{\text {DRV }}^{-}}{\gamma}$ and $\frac{\mathrm{d} \rho_{\text {CAV }}^{-}}{\gamma}$ are the dislocation annihilation rates due to dynamic recrystallisation, dynamic recovery and creep cavitation, respectively.

Rogowitz et al. (2016) have recently demonstrated in a fine-grained calcite ultramylonite $(\sim 3 \mu \mathrm{m})$ that recovery can occur without the formation of subgrain walls. Internal strain is recovered by extensive glide and dislocation networks characteristic of cross-slip and network-assisted dislocation movement. In conjunction with this mechanism, Rogowitz et al. (2016) also observed Zener-Stroh crack formation. This may outline a scenario in which cavity production dominates over subgrain wall formation.

While we infer Zener-Stroh cracking to be responsible for cavity nucleation, Hippertt (1994) proposed an alternative model to explain a concentration of pores on grain boundaries at high angles to the fabric attractor in a sheared micaceous quartzite (see Fig. 10 in Hippertt, 1994). Hippertt (1994) suggested that the initial porosity is loosely connected to the preferential dissolution of quartz at sites where dislocation tangles intersect grain boundaries (cf. Wintsch and Dunning, 1985). In both the sample of this study and of Hippertt (1994), there is a clear link between the pore orientation and the bulk finite strain. Considering the inferred orientations of compression and extension in our sample, preferential dissolution should be expected to be orthogonal to the observed cavities (see etch pit formation in Fig. 6d), i.e. creep cavities in our sample open at sites that would be favourable for precipitation, not dissolution. We therefore consider the model of Hippertt (1994) as incompatible with our observations.

\subsection{The role of creep cavities in the activation of GSS creep}

The rheological evolution of mid-crustal ultramylonites to GSS creep is prompted by the establishment of a very fine grain size. In ultramylonites that deform by GSS creep, grain growth is usually inhibited by the presence of secondary phases, a process called Zener pinning (Herwegh et al., 2011). When synkinematic creep cavities control fluid transport in ultramylonites (Fusseis et al., 2009; Menegon et al., 2015), cavities should also control secondary phase precipitation and hence directly influence Zener pinning (Herwegh and Jenni, 2001). This invites a discussion on how creep cavitation could influence Zener pinning and thereby facilitate the transition of a rock's rheology from GSI to GSS creep. A critical step in the rheological evolution of the ultramylonite investigated here is the transition from GSI to GSS creep in disintegrating quartz domains.

Conspicuously, secondary minerals are generally absent in the monomineralic quartz domains. We speculate that fluidfilled creep cavities will have affected grain-boundary migration directly by acting as pinning phases, therefore arresting grain sizes at sub-equilibrium dimensions and promoting the transition to VGBS. This idea can be further explored by combining our data with the Zener parameter, which quantifies the influence of second phases on rheology (Herwegh et al., 2011):

$Z=\frac{d_{\mathrm{sp}}}{f_{\mathrm{sp}}}$,

where $Z$ is the Zener parameter, $d_{\mathrm{sp}}$ is the size and $f_{\mathrm{sp}}$ is the volume fraction of the secondary phases. Equations (3) and (4) give an empirical indication of the value of $d_{\mathrm{sp}}$ for creep cavitation via Zener-Stroh cracking and VGBS, respectively. The dynamic nature of creep cavitation suggests that $d_{\mathrm{sp}}$ is not constant but varies between a maximum and a minimum that can be taken from Fig. 3a. However, it is unclear how $f_{\text {sp }}$ would evolve with the different cavity formation mechanisms. Any porosity derived exclusively from dislocation creep would be expected to have a characteristic spacing between pores on a grain boundary dictated by the crystal volume and the amount of strain that an individual slip system can accommodate. Therefore in this scenario $f_{\mathrm{sp}}$ would be directly linked to this characteristic spacing. On the other hand, values of $f_{\text {sp }}$ generated by porosity linked to VGBS would have a different character. The volume fraction in this case may be linked to a space problem in which the amount of dilatancy is limited by the surrounding grains. In either case, cavitation should be considered as a mechanism that is capable of evolving the Zener parameter and hence the rheology of a domain from GSI to GSS.

Our model ties in with more recent experimental observations by Précigout and Stünitz (2016), who also identify creep cavitation as a means of producing domains that deform by GSS creep. In contrast to our results, Précigout and 
Stünitz (2016) discuss the deformation of clinopyroxene embedded in an olivine matrix in which phase mixing occurs in clinopyroxene tails. This process is interpreted to be initiated by micro-cracking. Précigout and Stünitz (2016) advocate a model in which the nucleation rate of secondary phases is high. New phases are precipitated simultaneously with micro-cracking and each new cavitation site becomes filled with new phases, which suppresses the development of a CPO. On the other end of the spectrum, our observations highlight a scenario in which the rates of precipitation are so slow that cavities remain fluid filled. Evidence of quartz precipitation is possibly observed in the form of $\mathrm{Si}$ rich grain-boundary features (Fig. 6, see all blue arrows), but in our interpretation any precipitation is volumetrically not significant enough to fill cavities. Another major difference between the two models is that our model does not require brittle fractures to initiate the disaggregation of a monomineralic domain. The results of our work probably showcase an example in which the nucleation of phases is not kinetically or energetically favourable.

\subsection{A lack of boudinage but maintenance of strain compatibility}

A striking feature of the ultramylonite is the lack of any evidence for boudinage in quartz layers. This implies that either the synkinematic viscosity contrast between the polyphase and the quartz domains was small (Smith, 1975; Viegas et al., 2016), or that the quartz layer was not able to achieve localisation because the local temperature fluxes were efficiently dissipated (Peters et al., 2015). Boudinage by either of these processes is considered a ductile instability through which irrecoverable change occurs and grows over time (cf. Peters et al., 2015). In our sample a synkinematic porosity is observed and can itself be considered a ductile instability. As discussed above, creep cavitation by Zener-Stroh would be a dissipative feature of dislocation creep that would act to lower the internal energy of a grain. In thermodynamic terms, creep cavities could act as an energy sink. From a micromechanical perspective, a synkinematic porosity offers the possibly of lowering grain-boundary adhesion and cohesion as fluid is drawn to low-stress sites (Fusseis et al., 2009; Billia et al., 2013), thereby compromising the rheological integrity of the monomineralic quartz domains and promoting sliding. Therefore, it may be the case that cavity formation in quartz domains inhibits strain localisation via boudinage and the increase in the contribution of VGBS accommodates the extension of quartz layers, facilitating the quartz bands' ultimate demise.

\section{Conclusions and outlook}

In this study we utilise a workflow of SEM-based techniques and synchrotron $\mathrm{x}$-ray nanotomography to rigorously examine the nature and occurrence of a grain-boundary porosity found in recrystallised quartz ribbons of a quartzofeldspathic ultramylonite. We find that the porosity developed synkinematically from the deformation mechanisms active in quartz and the pores can thus be considered as creep cavities. We propose a model of hierarchical creep cavity formation that has implications for both the mircostructural and rheological maturation of an ultramylonitic fabric. We interpret based on the orientation of creep cavities and the crystallographic texture of quartz domains that Zener-Stroh cracking is responsible for the initial nucleation of creep cavities. The opening of creep cavities promotes the ingress of fluids to sites of low stress, and the local addition of a fluid lowers the adhesion and cohesion of grain boundaries, promoting VGBS. The increased activity of VGBS is documented in the thinning of quartz domains. In thinner quartz domains the texture weakens and cavities become more complex, eventually elongating. We suggest that cavitation at this stage of the quartz microstructural evolution is governed by VGBS. Zener-Stroh cracking can be directly linked to crystal plasticity, and our observations therefore potentially point to a wider significance of creep cavitation in mylonitic deformation. It remains unclear if the emergence of ZenerStroh cracking is contingent on quartz becoming the locally stronger phase. This would restrict the model presented here to scenarios in which some fine-grained mixtures have already emerged. Most importantly our findings document a micromechanical path for clustered quartz grains to be dispersed into a well-mixed phase mixture.

Both of the invoked creep cavity formation mechanisms are well known from material sciences and are intimately linked to ductile failure in metals and ceramics (Bauer and Wilsdorf, 1973; Gandhi and Ashby, 1979; Riedel, 1987; Shigematsu et al., 2004). Our model points to the coeval activity of both mechanisms in mid-crustal ultramylonites. This raises questions about how these creep cavities interact. While it is unclear if natural samples can reveal such transient aspects, it is clear that such questions are of critical importance in furthering our understanding of mylonitic processes and crustal deformation in general.

Data availability. The high-resolution BSE image is available from James Gilgannon (james.gilgannon@geo.unibe.ch).

\section{The Supplement related to this article is available online at https://doi.org/10.5194/se-8-1193-2017-supplement.}

Competing interests. The authors declare that they have no conflict of interest. 
Acknowledgements. We would like to thank Nicola Cayzer (Edinburgh Materials and Micro-Analysis Centre) and Natasha Stephen (Plymouth Electron Microscopy Centre) for their help with the acquisition of SEM data. James Gilgannon would like to thank Marco Herwegh for invaluable discussions about Zener pinning, Cees-Jan De Hoog for council on fluids and phase precipitation and finally Alfons Berger for EBSD procurement. We kindly thank the reviewers, Jacques Précigout and Luiz F. G. Morales, for their helpful reviews. This work was financially supported by the School of Geosciences, University of Edinburgh. Use of the Advanced Photon Source at Argonne National Laboratory was supported by the US Department of Energy, Office of Science, Office of Basic Energy Sciences under contract no. DE-AC02-06CH11357.

Edited by: Renée Heilbronner

Reviewed by: Luiz Morales and Jacques Précigout

\section{References}

Bauer, R. and Wilsdorf, H.: Void initiation in ductile fracture, Scripta Metall., 7, 1213-1220, https://doi.org/10.1016/00369748(73)90250-0, 1973.

Behrmann, J.: Crystal plasticity and superplasticity in quartzite; A natural example, Tectonophysics, 115, 101-129, https://doi.org/10.1016/0040-1951(85)90102-7, 1985.

Behrmann, J. and Mainprice, D.: Deformation mechanisms in a high-temperature quartz-feldspar mylonite: evidence for superplastic flow in the lower continental crust, Tectonophysics, 140, 297-305, https://doi.org/10.1016/0040-1951(87)90236-8, 1987.

Billia, M. A., Timms, N. E., Toy, V. G., Hart, R. D., and Prior, D. J.: Grain boundary dissolution porosity in quartzofeldspathic ultramylonites: Implications for permeability enhancement and weakening of mid-crustal shear zones, J. Struct. Geol., 53, 2-14, https://doi.org/10.1016/j.jsg.2013.05.004, 2013.

Caristan, Y.: The transition from high temperature creep to fracture in Maryland diabase, J. Geophys. Res.-Solid, 87, 6781-6790, https://doi.org/10.1029/JB087iB08p06781, 1982.

Cox, E. P.: A Method of Assigning Numerical and Percentage Values to the Degree of Roundness of Sand Grains, J. Paleontol., 1, 179-183, available at: http://www.jstor.org/stable/1298056, 1927.

Delle Piane, C., Wilson, C., and Burlini, L.: Dilatant plasticity in high-strain experiments on calcitemuscovite aggregates, J. Struct. Geol., 31, 1084-1099, https://doi.org/10.1016/j.jsg.2009.03.005, 2009.

Dimanov, A., Rybacki, E., Wirth, R., and Dresen, G.: Creep and strain-dependent microstructures of synthetic anorthitediopside aggregates, J. Struct. Geol., 29, 1049-1069, https://doi.org/10.1016/j.jsg.2007.02.010, 2007.

Etheridge, M. and Wilkie, J.: Grainsize reduction, grain boundary sliding and the flow strength of mylonites, Tectonophysics, 58, 159-178, https://doi.org/10.1016/0040-1951(79)90327-5, 1979.

Etheridge, M. A., Wall, V. J., Cox, S. F., and Vernon, R. H.: High fluid pressures during regional metamorphism and deformation: Implications for mass transport and deformation mechanisms, J. Geophys. Res.-Solid, 89, 4344-4358, https://doi.org/10.1029/JB089iB06p04344, 1984.
Fliervoet, T. F., White, S. H., and Drury, M. R.: Evidence for dominant grain-boundary sliding deformation in greenschistand amphibolite-grade polymineralic ultramylonites from the Redbank Deformed Zone, Central Australia, J. Struct. Geol., 19, 1495-1520, https://doi.org/10.1016/S0191-8141(97)00076X, 1997.

Fusseis, F., Handy, M., and Schrank, C.: Networking of shear zones at the brittle-to-viscous transition (Cap de Creus, NE Spain), J. Struct. Geol., 28, 1228-1243, https://doi.org/10.1016/j.jsg.2006.03.022, 2006.

Fusseis, F., Regenauer-Lieb, K., Liu, J., Hough, R. M., and De Carlo, F.: Creep cavitation can establish a dynamic granular fluid pump in ductile shear zones, Nature, 459, 974-977, https://doi.org/10.1038/nature08051, 2009.

Gandhi, C. and Ashby, M.: Overview no. 5: Fracturemechanism maps for materials which cleave: f.c.c., b.c.c. and h.c.p. metals and ceramics, Acta Metall., 27, 1565-1602, https://doi.org/10.1016/0001-6160(79)90042-7, 1979.

Handy, M. R.: Flow laws for rocks containing two non-linear viscous phases: A phenomenological approach, J. Struct. Geol., 16, 287-301, https://doi.org/10.1016/0191-8141(94)90035-3, 1994.

Herwegh, M. and Jenni, A.: Granular flow in polymineralic rocks bearing sheet silicates: new evidence from natural examples, Tectonophysics, 332, 309-320, https://doi.org/10.1016/S00401951(00)00288-2, 2001.

Herwegh, M., Linckens, J., Ebert, A., Berger, A., and Brodhag, S.: The role of second phases for controlling microstructural evolution in polymineralic rocks: A review, J. Struct. Geol., 33, 17281750, https://doi.org/10.1016/j.jsg.2011.08.011, 2011.

Herwegh, M., Poulet, T., Karrech, A., and Regenauer-Lieb, K.: From transient to steady state deformation and grain size: A thermodynamic approach using elasto-visco-plastic numerical modeling, J. Geophys. Res.-Solid, 119, 900-918, https://doi.org/10.1002/2013JB010701, 2014.

Hippertt, J. F. M.: Grain Boundary Microstructures in Micaceous Quartzite: Significance for Fluid Movement and Deformation Processes in Low Metamorphic Grade Shear Zones, J. Geol., 102, 331-348, https://doi.org/10.1086/629675, 1994.

Hirth, G. and Tullis, J.: The effects of pressure and porosity on the micromechanics of the brittle-ductile transition in quartzite, J. Geophys. Res.-Solid, 94, 17825-17838, https://doi.org/10.1029/JB094iB12p17825, 1989.

Huang, M., Rivera-Díaz-del-Castillo, P. E. J., Bouaziz, O., and van der Zwaag, S.: Modelling the steady state deformation stress under various deformation conditions using a single irreversible thermodynamics based formulation, Acta Mater., 57, 34313438, https://doi.org/10.1016/j.actamat.2009.03.023, 2009.

Hunter, J. D.: Matplotlib: A 2D graphics environment, Comput. Sci. Eng., 9, 90-95, https://doi.org/10.1109/MCSE.2007.55, 2007.

Ingebritsen, S. E. and Manning, C. E.: Permeability of the continental crust: dynamic variations inferred from seismicity and metamorphism, Geofluids, 10, 193-205, https://doi.org/10.1111/j.1468-8123.2010.00278.x, 2010.

Jones, E., Oliphant, T., Peterson, P., et al.: SciPy: Open source scientific tools for Python, http://www.scipy.org/ (last access: 13 December 2017), 2001.

Kerrich, R., Allison, I., Barnett, R. L., Moss, S., and Starkey, J.: Microstructural and chemical transformations accompanying deformation of granite in a shear zone at Miéville, 
Switzerland; with implications for stress corrosion cracking and superplastic flow, Contr. Mineral. Petr., 73, 221-242, https://doi.org/10.1007/BF00381442, 1980.

Kilian, R., Heilbronner, R., and Stünitz, H.: Quartz grain size reduction in a granitoid rock and the transition from dislocation to diffusion creep, J. Struct. Geol., 33, 1265-1284, https://doi.org/10.1016/j.jsg.2011.05.004, 2011.

Kruse, R. and Stünitz, H.: Deformation mechanisms and phase distribution in mafic high-temperature mylonites from the Jotun Nappe, southern Norway, Tectonophysics, 303, 223-249, https://doi.org/10.1016/S0040-1951(98)00255-8, 1999.

Mainprice, D., Hielscher, R., and Schaeben, H.: Calculating anisotropic physical properties from texture data using the MTEX open-source package, Geological Society, London, Special Publications, 360, 175-192, https://doi.org/10.1144/SP360.10, 2011.

Mancktelow, S. N., Grujic, D., and Johnson, L. E.: An SEM study of porosity and grain boundary microstructure in quartz mylonites, Simplon Fault Zone, Central Alps, Contrib. Mineral. Petr., 131, 71-85, https://doi.org/10.1007/s004100050379, 1998.

Menegon, L., Fusseis, F., Stünitz, H., and Xiao, X.: Creep cavitation bands control porosity and fluid flow in lower crustal shear zones, Geology, 43, 227-230, https://doi.org/10.1130/G36307.1, 2015.

Mitra, G.: Ductile deformation zones and mylonites; the mechanical processes involved in the deformation of crystalline basement rocks, Am. J. Sci., 278, 1057-1084, https://doi.org/10.2475/ajs.278.8.1057, 1978.

Paterson, M. S.: A theory for granular flow accommodated by material transfer via an intergranular fluid, Tectonophysics, 245, 135151, https://doi.org/10.1016/0040-1951(94)00231-W, 1995.

Peters, M., Veveakis, M., Poulet, T., Karrech, A., Herwegh, M., and Regenauer-Lieb, K.: Boudinage as a material instability of elasto-visco-plastic rocks, J. Struct. Geol., 78, 86-102, https://doi.org/10.1016/j.jsg.2015.06.005, 2015.

Poirier, J.: Shear zones in rocks Shear localization and shear instability in materials in the ductile field, J. Struct. Geol., 2, 135-142, https://doi.org/10.1016/0191-8141(80)90043-7, 1980.

Précigout, J. and Stünitz, H.: Evidence of phase nucleation during olivine diffusion creep: A new perspective for mantle strain localisation, Earth Planet. Sc. Lett., 455, 94-105, https://doi.org/10.1016/j.epsl.2016.09.029, 2016.

Précigout, J., Prigent, C., Palasse, L., and Pochon, A.: Water pumping in mantle shear zones, Nat. Commun., 8, 15736, https://doi.org/10.1038/ncomms15736, 2017.

Ree, J.-H.: Grain boundary sliding and development of grain boundary openings in experimentally deformed octachloropropane, J. Struct. Geol., 16, 403-418, https://doi.org/10.1016/01918141(94)90044-2, 1994.

Riedel, H.: Fracture at high temperatures, Springer-Verlag, Berlin, Heidelberg, 1987.

Rogowitz, A., White, J. C., and Grasemann, B.: Strain localization in ultramylonitic marbles by simultaneous activation of dislocation motion and grain boundary sliding (Syros, Greece), Solid Earth, 7, 355-366, https://doi.org/10.5194/se-7-355-2016, 2016.

Rovetta, M. R., Delaney, J. R., and Blacic, J. D.: A record of high-temperature embrittlement of peridotite in $\mathrm{CO}_{2}$ permeated xenoliths from basalt, J. Geophys. Res.-Solid, 91, 3841-3848, https://doi.org/10.1029/JB091iB03p03841, 1986.
Rybacki, E., Wirth, R., and Dresen, G.: High-strain creep of feldspar rocks: Implications for cavitation and ductile failure in the lower crust, Geophys. Res. Lett., 35, L04304, https://doi.org/10.1029/2007GL032478, 2008.

Schindelin, J., Arganda-Carreras, I., Frise, E., Kaynig, V., Longair, M., Pietzsch, T., Preibisch, S., Rueden, C., Saalfeld, S., Schmid, B., Tinevez, J.-Y., White, D. J., Hartenstein, V., Eliceiri, K., Tomancak, P., and Cardona, A.: Fiji: an open-source platform for biological-image analysis, Nat. Meth., 9, 676-682, https://doi.org/10.1038/nmeth.2019, 2012.

Shigematsu, N., Fujimoto, K., Ohtani, T., and Goto, K.: Ductile fracture of fine-grained plagioclase in the brittleplastic transition regime: implication for earthquake source nucleation, Earth Planet. Sc. Lett., 222, 1007-1022, https://doi.org/10.1016/j.epsl.2004.04.001, 2004.

Smith, R.: Unified theory of the onset of folding, boudinage, and mullion structure, Geol. Soc. Am. Bull., 86, 1601-1609, https://doi.org/10.1130/00167606(1975)86<1601:UTOTOO>2.0.CO;2, 1975.

Stipp, M., Stünitz, H., Heilbronner, R., and Schmid, S. M.: The eastern Tonale fault zone: a "natural laboratory" for crystal plastic deformation of quartz over a temperature range from 250 to $700{ }^{\circ}$ C, J. Struct. Geol., 24, 1861-1884, https://doi.org/10.1016/S0191-8141(02)00035-4, 2002.

Stroh, A.: A theory of the fracture of metals, Adv. Phys., 6, 418465, https://doi.org/10.1080/00018735700101406, 1957.

Teyssier, C.: High strain zones in the continental crust: the central Australian example, PhD thesis, 1985a.

Teyssier, C.: A crustal thrust system in an intracratonic tectonic environment, J. Struct. Geol., 7, 689-700, https://doi.org/10.1016/0191-8141(85)90144-0, 1985 b.

Tullis, J.: Deformation of Granitic Rocks: Experimental Studies and Natural Examples, Rev. Mineral. Geochem., 51, 51-95, https://doi.org/10.2138/gsrmg.51.1.51, 2002.

van der Walt, S., Colbert, S. C., and Varoquaux, G.: The NumPy Array: A Structure for Efficient Numerical Computation, Comput. Sci. Eng., 13, 22-30, https://doi.org/10.1109/MCSE.2011.37, 2011.

Viegas, G., Menegon, L., and Archanjo, C.: Brittle grain-size reduction of feldspar, phase mixing and strain localization in granitoids at mid-crustal conditions (Pernambuco shear zone, NE Brazil), Solid Earth, 7, 375-396, https://doi.org/10.5194/se-7-375-2016, 2016.

Wintsch, R. P. and Dunning, J.: The effect of dislocation density on the aqueous solubility of quartz and some geologic implications: A theoretical approach, J. Geophys. Res.-Solid, 90, 3649-3657, https://doi.org/10.1029/JB090iB05p03649, 1985.

Wong, T.-F.: A note on the propagation behavior of a crack nucleated by a dislocation pileup, J. Geophys. Res.-Solid, 95, 86398646, https://doi.org/10.1029/JB095iB06p08639, 1990.

Závada, P., Schulmann, K., Konopásek, J., Ulrich, S., and Lexa, O.: Extreme ductility of feldspar aggregates - Melt-enhanced grain boundary sliding and creep failure:Rheological implications for felsic lower crust, J. Geophys. Res.-Solid, 112, B10210, https://doi.org/10.1029/2006JB004820, 2007. 